\title{
Efficiency and returns to scale in the Bangladesh banking sector: empirical evidence from the slack-based DEA method
}

\begin{abstract}
The study provides new empirical evidence on the level of profit efficiency and returns to scale of the Bangladesh banking sector. We employ the Slack-Based Data Envelopment Analysis (SBM-DEA) method to assess the level of profit efficiency of individual banks over the years 2004 to 2011. The empirical findings indicate that the Bangladesh banking sector has exhibited the highest and lowest level of profit efficiency during years 2004 and 2011 respectively. We find that there are only eight banks have been profit efficient throughout the period under study. The empirical findings seem to suggest that most of Bangladesh banks have been experiencing economies of scale due to being at less than the optimum size, or diseconomies of scale due to being at more than the optimum size. Thus, decreasing or increasing the scale of production could result in cost savings or efficiencies.
\end{abstract}

Keyword: Banks; Profit efficiency; Slack-based data envelopment analysis; Returns to scale; Bangladesh 